\title{
La vanguardia de Valparaíso: expresionismo de/en la periferia*
}

\author{
Valparaíso avant-garde: expressionism of/in the periphery
}

\author{
Adolfo de Nordenflycht Bresky
}

\begin{abstract}
Pontificia Universidad Católica de Valparaíso, Instituto de Literatura y Ciencias del Lenguaje. Correo electrónico: adolfodenordenflycht@gmail.com
\end{abstract}

El presente artículo constituye una revisión respecto de la producción literaria de vanguardia en Valparaíso, en la primera mitad del siglo XX. Proponemos que en Valparaíso, a diferencia de la vanguardia metropolitana que privilegió el magisterio del creacionismo huidobriano, se desarrolló -en virtud de las peculiaridades del espacio local- una vanguardia de carácter expresionista, que ha sido escasamente considerada en la historia de la literatura nacional. Sostenemos que este rasgo diferencial fue estimulado por la presencia del húngaro Zsigmond Remenyik y los textos de su autoría incluidos en Las tres tragedias del lamparero alucinado, como también por El aullido de las rameras, de Julio Walton, ambos de 1922.

Palabras clave: vanguardia expresionista, Valparaíso, literatura local, periferia, espacio de representación.

This article is a revision on the avant-garde literary production in Valparaiso, in the first half of the twentieth century. We propose that in Valparaiso, in contrast to the metropolitan avant-garde that favored the teaching of Huidobro's creationism, was developed - under the peculiarities of local space- an expressionist avant-garde, which has been rarely seen in the history of national literature. We argue that this distinguishing feature was stimulated by the presence of Hungarian activist Zsigmond Remenyik and the texts of his authorship included in Las tres tragedias del lamparero alucinado since also for Julio Walton's El aullido de las rameras, both written in Valparaiso in 1922.

Key words: expressionist avant-garde, Valparaíso, local literature, periphery, space of representation.

\footnotetext{
* Este artículo se inscribe en el marco del Proyecto Fondecyt $\mathrm{N}^{\circ} 1085201$ "Constelaciones del imaginario local en la literatura de Valparaíso (1888-1989): Procedencias y emergencias”. Investigador Responsable: Adolfo de Nordenflycht.
} 


\section{INTRODUCCIÓN}

En los estudios sobre la literatura de Chile se ha desatendido a un número no menor de autores que desarrollaron su producción en el espacio local de provincias y regiones, quedando muchas veces reducidos a una simple mención, o bien totalmente marginados del canon nacional que se ha configurado, en sus versiones más triviales (entre otras, las del canon escolar), como una reposición orientada a potenciar determinados "valores" acoplados en una trama que tiende a dar una imagen axiomática (Chile país de poetas), triunfalista (dos premios nobeles de literatura), incluso mesiánica (Huidobro iniciador de las vanguardias en lengua hispana), de la identidad cultural y literaria nacional.

Las antologías, los manuales, los diccionarios de autores y otras modalidades que recogen y difunden lo que podríamos reconocer como itinerario crítico de curso nacional, evidencian esta situación, que se corresponde con formas de historización, parcial y relativa, realizadas normalmente desde la metrópolis; estas no cuestionan la idea de nación unitaria a la que contribuye la propuesta de una literatura que se quiere nacional, conduciendo su atención a realizar inventarios de obras y autores supuestamente representativos de una determinada época o tendencia y destacando el papel que tales obras y autores vendrían a desempeñar respecto de la identidad cultural nacional.

En buenas cuentas, la intención de establecer un ordenamiento de la totalidad ha terminado por convertirse en una perspectiva que tacha las diversidades entre las diversas literaturas de Chile, silenciándolas en una entelequia unitaria y subsumiéndolas en macrodiscursos que encubren la propuesta fraguada desde los centros de poder intelectual y cultural metropolitanos que sancionan la incorporación al "canon nacional": De esta manera se han erradicado o marginalizado, entre otras, las literaturas producidas en las regiones, zonas, localidades o provincias, esto es, en lo que recurriendo a Lefebvre (Oslender 2005 en línea), podemos reconocer como "espacio subalterno localizado". Si una de las proposiciones del proyecto fundador de Lastarria (1842) se orientaba a constituir una literatura afincada en lo propio nacional, la prosecución de tal empeño diferenciador generó a su vez, y por largo tiempo, una inhabilidad en la crítica para percibir la heterogeneidad y la diferencia al interior de este hecho.

Es cierto que la consideración de la diferencia ha sido uno los aspectos que ha ocupado un lugar medular en la reflexión de las ciencias sociales y las humanidades del siglo XX. Al margen de pensadores como Lacan, Foucault, Derrida, Deleuze, Butler, entre otros, que se han comprometido en el estudio de la diferencias, ya desde los inicios de la indagación teórica sobre la literatura tanto Bajtin como los formalistas rusos afirmaban la relevancia de esta noción, tanto así que Tinianov en 1927 reconocía que "la existencia de un hecho como hecho literario depende de su cualidad diferencial" (Todorov 1970: 92). Pero fue Gilbert Chaitin (1989-1997) quien, desde el ámbito de los estudios de literatura comparada, propuso una "literatura diferencial", sustentándola en la denominada séptima hipótesis de Parménides, de acuerdo a la cual:

ni la totalidad ni lo individual existen en sí mismos ni por sí mismos, sino que lo individual es producto de las diferencias con los otros; y la totalidad no puede existir de forma independiente, ya que entonces no habría nada de lo que diferir, excepto de la no-existencia, de la nada (156). 
De modo que en el proceder de la literatura diferencial, en vez de imponer una unidad pretextada por "una supuesta objetividad, se buscaría la liberación de diferentes voces para dejarlas ser en su otredad" (163). Sin ocuparnos de los argumentos de Jesús G. Maestro (2009. En línea) que intentan descalificar esta propuesta tachándola de posmoderna y que lo conducen a afirmar que "esa diferencia $[\ldots]$ en los términos que nos la describe Chaitin, confieso no saber en absoluto ni de qué se trata ni en qué consiste", creemos que los procesos de canonización nacional ineludiblemente dan pie al reconocimiento de "diferentes voces" que se registran en los espacios subnacionales.

Los procesos de constitución del canon nacional generan direcciones centrípetas y centrífugas, que se articulan operando con criterios de identidad nacional y de natalicio o linaje, a la par que criterios estético-críticos, desarrollando una construcción selectiva que incorpora, entroniza y consagra ciertas producciones, al tiempo que relega como desechos prescindibles otros textos y autores a la periferia de lo local. Por su parte, desde lo local se busca el modo de validar eventuales incorporaciones al canon nacional o de asociar la realidad local a las determinaciones exitosas nacionales. En todo caso, los trabajos existentes en esta última dirección terminan por limitarse a recopilaciones antológicas ordenadas cronológicamente; a constatar cómo la sociedad, los periodos históricos y los espacios locales se hallan reflejados en obras de ficción, o bien a monografías sobre autores ligados a la provincia o región. Todo ello ha favorecido la existencia de un cúmulo disperso y amorfo de informaciones que, si presenta alguna formalidad, ella proviene de la reproducción de los paradigmas crítico-literarios nacionales y supranacionales. Jacqueline Cruz (1997), sosteniendo que las vanguardias constituyen procesos de autoafirmación de individuos, sectores o países marginales, sostiene que:

La contradicción se halla en que, pese al afán de autoafirmación que motiva este proyecto, la metrópoli constituye un referente constante en su obra, lo cual no hace sino reforzar su carácter de "centro" como señala Nelly Richard, éste deriva su autoridad sobre todo del hecho de ser considerado como fuente de todo significado, y facilita, además, que las innovaciones impulsadas por las regiones periféricas sean absorbidas por los centros metropolitanos, los cuales instituyen, a la larga, un canon selectivo que las excluye nuevamente (29).

En este proceso, lo que adquiere significado, aunque sea por absorción, se constituye en historia; lo excluido de regreso a la región se conserva, en cambio, como memoria. Ahora bien, Pierre Nora (2002) sostiene que, luego de la conocida propuesta de Halbwachs, la 'memoria' ha ido adquiriendo un significado muy amplio y dominante que tiende claramente a substituir al término 'historia', y "a poner la práctica de la historia al servicio de la memoria" (Nora 2002: 29). Si bien Nora denuncia la condición maniquea, distorsionadora y simplificadora de la memoria colectiva, no deja de reconocerle su carácter emancipador y liberador, como también el rasgo de fidelidad que la determina, esto es:

la pretensión de la memoria colectiva a una verdad más 'verdadera' que la verdad de la historia, la verdad de lo vivido y de lo recordado -recuerdo del dolor, de la opresión, de la humillación, del olvido-, cualquiera sea, en síntesis, la parte de reconstrucción y de reconducción artificial de esta memoria (Nora 2009, p. 29). 
Desde la perspectiva de la práctica social parece cierto que la memoria colectiva posibilita la reflexión sobre los aspectos éticos y políticos involucrados en los acontecimientos pasados, en particular los hechos traumáticos que, en cambio, desde la perspectiva de la historia, debido a su capacidad crítica y explicativa, serían racionalizados y perderían su afectividad y carácter único. Nora acepta que la confusión entre memoria e historia es propia de la dinámica social, pero la única manera de no volverse esclavo de ella es convertirse en crítico de la historia misma. En nuestro caso, historia literaria que, consolidándose mediante los procesos de canonización metropolitanos, excluye y relega numerosos textos a la periferia local, al espacio de la memoria donde articulan vagamente una literatura diferencial.

De este modo, lo que se reconoce como literatura de vanguardia en Chile quedaba hasta hace poco tiempo limitada a tres o cuatro nombres, inevitables sin duda en tanto se trata de textos y autores que se han impuesto por una suerte de peso específico (Huidobro, Neruda, De Rokha, incluso Mistral; a los que se añaden Rosamel del Valle, Díaz Casanueva, los poetas de Mandrágora y esporádicamente algunos otros, casi siempre de manera esquemática y ensombrecidos por el olvido); cuando no se opera así, se habla de generaciones o movimientos que acompañan a esos grandes nombres, criterio que a su vez no deja de ser "monolítico y jerarquizante" (como reconoce Vergara 1994: 3).

Si bien el surgimiento y expansión de las vanguardias históricas se corresponde con lo que Compagnon (1990) ha reconocido como la segunda crisis de la modernidad, que sobreviene junto con los procesos de modernización que plasman la "conciencia histórica del tiempo", no hay duda que en nuestro ámbito fue la emergencia y afianzamiento de la nación la que impulsó primeramente la modernidad. No obstante, pensar esta última como un fenómeno homogéneo y simultáneo, es al menos deficitario. De acuerdo a Renato Ortiz (2001), la modernidad corresponde a un fenómeno múltiple, en tanto se realiza de manera distinta en correspondencia con las condiciones históricas de cada lugar y por ello la modernidad es, a la vez, una y diversa. Una, en cuanto a procesos que le son consustanciales (la modernización); diversa, en su configuración histórica, sujeta a un tiempo-espacio particular que le asigna diferencialidad a cada proceso.

Por tanto, la modernidad no corresponde a un proceso que se traslade desde las metrópolis de turno a los bordes; ninguna modernidad resulta modelo para las otras, ya que no es un fenómeno que se desarrolla por imitación. Se trata más bien de un conjunto de cambios correspondientes a una "lógica interna" a decir de Morse (2005. En línea), en las historias específicas de cada localidad, de esos otros espacios urbanos que participaron como "arenas culturales" (Morse 2005), al menos en algún momento del proceso de lo moderno, lo que las convierte, utilizando un concepto de Foucault (1967. En línea), en especies de "heterotopías crónicas", es decir, espacios otros que ostentan esta condición por un periodo de tiempo fugaz, transitorio, sosteniendo este sitial mientras sus ventajas geográficas y naturales fueron funcionales a las metrópolis del momento, como lo fuera el puerto de Valparaíso en relación a Santiago y también a la red logística de puertos que se disputaron las potencias marítimas durante el siglo XIX e inicios del XX. En este contexto nos proponemos revisar algunos textos de la producción literaria de la vanguardia desarrollada en el espacio local de Valparaíso, que escasamente ha sido considerada en sus particularidades en tanto proceso evolutivo diferencial. 


\section{II. ¿“UNA Historia APARTE”?}

Tal vez sea Claudio Solar (2001) quien ha avanzado más recientemente en el intento de construir una historia de la literatura de Valparaíso, si bien su esfuerzo, que presenta numerosos descuidos en su redacción y confusión en las informaciones, termina orientándose a una historiografía ordenada conforme un criterio que reproduce "a escala" los procesos y tendencias observados por la crítica en la literatura nacional, a lo que se añaden, casi como curiosidades pintorescas, datos que asocian a autores, obras y movimientos, exitosos nacionalmente, con la intrahistoria local.

En la introducción de su historia y bajo el título de "Anotaciones para una Historia de la Literatura de Valparaíso", Solar expone el propósito y alcance de su trabajo, señalando que la mayor de las dificultades se debe a que "la creación literaria no ha marchado al mismo paso que la de la metrópoli" (5), lo cual argumenta recordando que el Modernismo se habría iniciado en Valparaíso "(con la publicación de Azul de Darío, aunque muchos poetas se han quedado hasta hoy en el pasado romántico)", como también que Valparaíso es "pionero" en la poesía y la novela social (entre los poetas distingue a Zoilo Escobar y Pezoa Véliz, en novela ¡Krack! de Ventura Fraga), pero que no ocurrió lo mismo con otros movimientos como el realismo o el naturalismo. Por otra parte, el criollismo no tiene representación en la novelística porteña, pues según Solar esta continuó apegada a un tardío realismo balzaciano. En adelante, se señala que la literatura de Valparaíso corresponde a "ecos" de los movimientos metropolitanos: creacionismo, surrealismo, generación del 38, del 54, destacando autores que habrían practicado y dado a conocer a nivel local dichas tendencias nacionales o internacionales. Todos a destiempo y sin reconocimiento "en el parnaso santiaguino".

Solar concluye la introducción afirmando que: "Valparaíso y Santiago son dos países diferentes cuando se trata de hablar de literatura. Cada uno tiene la suya. Dejémoslo así. Es lo que justifica estas 'Anotaciones para una Historia Aparte"'(6). No explica, sin embargo, su aseveración. ¿Qué puede entenderse como una historia aparte, si anteriormente se ha limitado a señalar los destiempos que habría en la literatura de Valparaíso siempre en relación con la historia literaria nacional, establecida desde una perspectiva y de una canonización metropolitana? ¿Una historia aparte, tendría que prescindir de estas relaciones de dependencia? ¿Aparte implica separar, omitir, distanciar, alejar, relegar, rechazar o distinguir? Pareciera que esto último es a lo que se quiere aludir si se considera la metafórica expresión "dos países diferentes".

El asunto, sin embargo, es que a lo largo de su propuesta historizadora no resulta posible reconocer otra diferencia que distinga ambas literaturas ("cada uno tiene la suya"), que no sean el dato de nacimiento o avecindamiento, o bien, la referencia directa y pintoresca a la ciudad-puerto. Y, por cierto, no hace cuestión alguna de la escritura de vanguardia en Valparaíso, que se limitaría a ser una reproducción de los movimientos (creacionismo, surrealismo, son los que menciona el historiógrafo) desarrollados con anticipación en la metrópolis.

\section{ESCRITURA DE VANGUARDIA EN EL ESPACIO LOCAL}

A mi juicio, estas afirmaciones de Solar no parecen del todo justas y requieren de otras consideraciones, al menos respecto de las vanguardias, que en el caso de Chile 
tienen su primera y debatida manifestación en el artículo Non serviam que Huidobro habría leído en 1914 en el Ateneo de Santiago. No voy a discutir aquí el asunto de la periodización de las llamadas vanguardias históricas, aceptando provisoriamente la propuesta de Schwartz (1991) que señala precisamente este texto huidobriano como "la fecha más apropiada para la inauguración de las vanguardias latinoamericanas" (29). En lo que sí todos los críticos parecen estar de acuerdo es en la importancia del año 1922, el annus mirabilis, que es la fecha propuesta por Borges en el Índice de la nueva poesía americana aparecido en 1926, como "iniciadora de una nueva era en las letras" (Schwartz, 29). En Chile no surgen otras manifestaciones de la "sensibilidad nueva" tras las propuestas huidobrianas, quien en 1916 publica la controvertida plaquette Espejo de Agua.

La actividad propiamente vanguardista no parece tener seguidores inmediatos en Santiago, que es sin duda el centro de la actividad literaria nacional. La ausencia de Huidobro y la fuerte presencia del modernismo crepuscular del grupo Los Diez, la lírica que empieza a desarrollar Gabriela Mistral, el neorromanticismo de Neruda en Crepusculario, no parecen dejar mucho espacio a las renovaciones vanguardistas. El único que parece aproximar un paso más decidido hacia el lenguaje de la vanguardia es De Rokha con Sátira (1918), a lo que se añade un par de años después, en noviembre de 1920, la publicación en la revista santiaguina Claridad del Primer Manifiesto "Agú", de inspiración dadaísta: "Agú. Lo elemental. La voz alógica / El primer grito de la carne" (1920: 7), pero también con trazos futuristas y ultraístas, "Reivindiquemos el sobresalto, la caricia fugaz, el mordisco... /La tristeza de la grasa sobre el abdomen.../ El juego de los músculos" (id); manifiesto-poema que se debe al porteño Alberto Rojas Jiménez (fundador y primer director de la revista), junto a Martín Bunster. Nunca se constituyó "Agú" como un grupo y todo parece haber quedado en este manifiesto un tanto juguetón y escasamente programático. En provincias la situación es distinta, y tal vez por el vacío de voces poéticas que se trasladaron a la capital, el terreno parecía más proclive para la experimentación de los jóvenes.

Es así como al año siguiente, en 1921, aparece un pequeño volumen firmado por Jacques Edwards, "Chargé d'affaires DADA au Chili", que no es otro que el porteño Joaquín Edwards Bello, que en 1919 había sido "proclamado presidente DADÁ por Tristan Tzara en la proclamación universal de presidentes en el Salón des Independants, Paris" como se asegura al inicio del texto. EI volumen de 1921 que se titula Metamorfosis se autodesigna como "folleto [que] contiene composiciones ultraístas y dadaístas" y está dedicado a Tristan Tzara, "inventor de la lengua francesa". En efecto, se trata de una mezcla de imágenes ultraístas y de propósitos dadaístas. Así, en el primer poema se manifiesta: "Rebusca estética hasta el infinito, / sujetándose a las normas de la concentración espiral y rotatoria" (Edwards 1979: 14), donde es evidente la recurrencia a la imagen ultraísta de la espiral, que además es el título del poema. El texto concluye con una suerte de proclama: "DADA destruirá a DADA /.... DADA es fermento astronómico, oblongo, gaseoso sin exageración y de color amarillo. / Pero no significa nada" (15), donde la alusión al primer manifiesto de Tzara es obvia. Este reclamo por asociarse a DADÁ, que puede resultar un tanto ingenuo y afectado, revela, a nuestro parecer, un afán de distanciarse de la vanguardia orgánica dispuesta desde la metrópolis y patrocinada desde París por Huidobro, abriendo posibilidades a otras experiencias de arte nuevo (aunque en el caso de Edwards parece haberse tratado de una moda pasajera) en un espacio periférico divergente de la hegemonía 
creacionista, que sin embargo resulta muy persistente en los poemas de Salvador Reyes incorporados en el Indice de la nueva poesía americana ${ }^{1}$.

\section{La Rosa NÁUtica: De Agrella a RemenyiK}

En los primeros meses de 1922 -la fecha es incierta- ${ }^{2}$ aparece en Valparaíso un "cartel" editado por la Editorial Tour Eiffel; se trata de un volante que se presenta como Antena, Hoja vanguardista $N^{\circ} 1$, que consiste en el manifiesto titulado Rosa Náutica, junto a un grabado del húngaro Sandor Bortnyik que se titula "Aktivizmus". Entre los firmantes que se reconocen a sí mismos como "La dirección del movimiento vanguardista chileno" figuran los ya citados Alberto Rojas Jiménez y Martín Bunster, responsables del manifiesto Agú. Y además, de un total de 25, están Neftalí Agrella que encabeza el listado, Julio Walton, Salvador Reyes, el mexicano Carlos Toro, Marko Smimoff (que conocía bien la vanguardia rusa) y el húngaro Zsigmond Remenyik que había militado en el activismo liderado por Kasack. Adhieren al manifiesto: Huidobro, Edwards, Borges, Maples Arce, Guillermo de Torre y Norah Borges. Rosa Náutica ${ }^{3}$ es provocativamente contestatario de la tradición modernista, y empleando un tono irónico quiere poner a la literatura chilena en consonancia con las prácticas vanguardistas que ya estaban bien aclimatadas en otras latitudes. En Europa, que es considerada como el enorme tablero eléctrico desde donde:

parten incontables ISMOS, cables submarinos o terrestres que han buscado los intersticios eocénicos, transpasando invertebradamente los estratos seculares para transmitir a las 4 esquinas de la Rosa Náutica la nueva vitalidad eléctrica, la futurista sensibilidad y la debiscencia jugosa del humour que en Europa, corazón del planeta, han sustituido a los ancestralismos fatalistas (Osorio 1988: 119).

Como puede apreciarse, los jóvenes vanguardistas firmantes del manifiesto, que se señalan a sí mismos como la "generación naciente", conceden que los "ismos" son innumerables, pero reconocen que ésta surge en el ámbito abierto por el futurismo, el cubismo literario y el creacionismo, siendo Huidobro el único poeta latinoamericano que es nombrado positivamente en Rosa Náutica. "Hemos nacido en el Espíritu Nuevo de Apollinaire, Marinetti, Huidobro" (Osorio, 121). No se hace referencia al dadaísmo, en el que se pretendía instalar Edwards, ni tampoco al expresionismo, tal

\footnotetext{
${ }^{1}$ Salvador Reyes participó de la vanguardia de Valparaíso siendo uno de los firmantes de Rosa Náutica y permaneciendo siempre muy ligado a las iniciativas literarias surgidas en el Puerto. En la sección del prólogo al Indice escrita por Borges, tras afirmar que "Desde mil novecientos veintidós [...] la verdad poetizable ya no está solo allende el mar", sugiere que tal verdad está en la peculiar existencia cotidiana de la ciudad latinoamericana moderna, y entre otros ejemplos, indica: "En Chile, Reyes ensalza el cabaret y el viento del mar, un viento negro y de suicidio, que trae aves marinas en su envión y en el cual las persianas de Valparaíso están siempre golpeándose" (Indice, 2007:24). Nos parece que más allá de las similitudes de los poemas de Reyes con los Poemas árticos de Huidobro, Borges con lucidez percibe en ellos un espacio local que describe con tintes expresionistas.

${ }^{2}$ En la reproducción facsimilar reducida se puede leer: "En junio aparecerá el primer número de nuestro Ideario de Arte y Literatura actual, Tour Eiffel" (véase Zsigmond Remenyik: 2009).

${ }^{3}$ El manifiesto Rosa Náutica se encuentra recogido en Nelson Osorio (1988), por quien citamos.
} 
vez por ser considerado como una postura vital más que como un "ismo", pero que, a nuestro juicio, tendrá sobresaliente relevancia en la vanguardia porteña.

Tanto Osorio (121) como Schwartz (1991: 69-70) destacan la presencia de Remenyik entre los firmantes y este último, recogiendo sugerencias de László Scholz, le atribuye la introducción de la estética del activismo húngaro y vienés en el medio vanguardista porteño. Ferdinandy (1975), además, ha aportado como documento otro cartel que lleva el $\mathrm{N}^{\circ}$ IlI, también de 1922, firmado únicamente por Remenyik, que ese mismo año publica en Valparaíso La tentación de los asesinos bajo el sello editorial Tour Eiffel $^{4}$, luego incluido en Las tres tragedias del lamparero alucinado ${ }^{5}$. El cartel está escrito en primera persona singular y tiene un tono muy diferente a Rosa Náutica, lo cual nos inclina a pensar que Rosa Náutica tuvo como principal redactor a otro de los firmantes, más allá de los aportes que pueda haber realizado Remenyik ${ }^{6}$. Probablemente Neftalí Agrella que encabezaba al grupo vanguardista porteño. Es posible que en el texto de Rosa Náutica, que incorpora "algunas extrañas imágenes" (Schwartz: 69), haya "indicios de la influencia del activismo alemán-húngaro" como apunta Scholz (1980: 90), pero es aún más nítido el reclamo de fondo por un espacio intelectual para la juventud y la nueva sensibilidad vanguardista; Agrella ya había destacado en un artículo de 1921 publicado en un diario antofagastino que "Nunca la poesía joven de este país ha sido reconocida plenamente. Sin embargo hay en Valparaíso más de un grupo juvenil (...) (Agrella 1921 [1999]: 2597)". También nos parecen de Agrella las metáforas modernólatras (provenientes de un modernismo tardío del que fuera cultor en sus primeros años), los calificativos ampulosos, ahora con una función irónica, y el humor burlón que por los mismos años permeaban los hai-kais de Agrella. No obstante, lo que sí parece importante reconocer es el aporte activista de Remenyik, que va a dar un sello particular a la vanguardia porteña y que en el ámbito nacional va a incorporarse en fecundo diálogo con la poesía de raigambre popular de De Rokha, a

\footnotetext{
${ }^{4}$ Scholz (1980: 91) afirma que: "Lo escribió en los últimos días de 1921 y la Editorial Tour Eiffel de Valparaíso lo lanzó a los lectores en agosto de 1922”.

Nos ha sido imposible consultar la edición original, no obstante Scholz, en el prólogo a Zsigmond Remenyik (2009: 14), en que se incluye este texto con una reproducción de su portada original, señala que Remenyik es determinante, a no ser que se suponga que actuó al margen de los otros firmantes en el proceso de edición del texto y en particular de Agrella y Walton que fueron los responsables de la editorial Tour Eiffel. Nos inclinamos a pensar que estos errores ortográficos, que resultan mínimos en relación con la escritura de los posteriores textos en español de Remenyik, que tendía a acentuar agudamente, no son más que erratas de imprenta.

5 "Poetas chilenos", publicado originalmente en Diario "El Abecé”, Año I, Núm. 149, jueves 10 de marzo de 1921, Antofagasta. Este artículo figura como "Introducción” a la sección "Literatura Chilena” en Agrella (1999: 259-260); edición de la cual citamos; se trasladó al Perú "adonde llegó a fines de 1922 y donde continuó publicando obras en español. En 1923 publicó en Agitación, casa editorial limeña un volumen que contenía tres epopeyas probablemente todas escritas todavía en Chile [...]. El libro lleva por título Las tres tragedias del lamparero alucinado".

${ }^{6}$ Scholz en el prólogo citado (Remenyik 2009: 12) concluye que es "difícil saber hasta qué punto participó Remenyik en la redacción de este texto cosmopolita y ecléctico", no obstante en nota a pie de página comenta: "Los errores ortográficos -como por ejemplo la omisión de acentos (corazon) o los acentos mal colocados (Cárlos) - son típicos de sus obras posteriores". El argumento no nos parece determinante, a no ser que se suponga que Remenyik actuó al margen de los otros firmantes en el proceso de edición del texto y en particular de Agrella y Walton que fueron los responsables de la editorial Tour Eiffel. Nos inclinamos a pensar que estos errores ortográficos, que resultan mínimos en relación con la escritura de los posteriores textos en español de Remenyik, que tendía a acentuar agudamente, no son más que erratas de imprenta.

7 "Poetas chilenos", ya cit. Este artículo figura como "Introducción" a la sección "Literatura Chilena" en Agrella (1999: 259-260); edición de la cual citamos.
} 
partir de $U$ en 1926. Por otra parte, el propio Remenyik parece reconocer en la figura de Agrella el más emblemático exponente de la vanguardia de Valparaíso. Es así como en 1929, ya de vuelta en Hungría, escribe en deficiente español un extenso texto en prosa titulado Los juicios del Dios Agrella. Al parecer, en este texto, redactado ya lejos de Valparaíso, Remenyik quiere dar testimonio del grupo vanguardista porteño liderado por Agrella, sirviéndose de datos biográficos que transfigura en un relato orientado a construir el mito de Agrella y junto a ello el mito fundante de la vanguardia porteña. Remenyik describe con crudeza y feísmo la atmósfera lúgubre de los bajos fondos del Valparaíso de los años 1920: la miseria, el alcoholismo, la prostitución, la delincuencia, que articulan un mundo de seres marginados (marineros, vagabundos, pescadores, lavanderas, mendigos, anarquistas, prostitutas), entre los que se encuentran los poetas y artistas de vanguardia que siguen al "Dios" Agrella como discípulos. El personaje Agrella relata a un grupo de porteños sus andanzas por Nueva York, donde conoce a Marinetti, su correspondencia con Apollinaire y Trotski, sus lecturas de Marx, Voltaire, Swift, Spinoza, Whitman, Rousseau, en fin, su vida de vagabundaje y sus ideas anarquistas, porque:

Agrella era un anárquista, no solamente en su pensár i juiciós, sinó en su vida tambien! (...) Agrélla ni há creidó en los hombres perfectós, igualmente comó no há creidó en lás ideás perfectás! (...) no há creidó en los dióses, por lo ménos en dióses perfectós no há creidó! (...) infinitamente há despreciado la mentira, esta piedra fundamental de la actuál sociedád! sin embargó há mentido él tambien, comó tódós los que él despreciába! (...) era hambientó tambien, hambrientó i rotósó! (Remenyik 2009: 188-189 [sic]).

A lo largo del relato se nos revela cómo el Dios Agrella, que se asemeja más a un Cristo vagabundo y anarquista, un Dios hecho hombre que padece y comprende las miserias y flaquezas humanas, pues las vive en su propia existencia, realiza una suerte de peregrinaje místico durante el cual va experimentando, reflexionando y escribiendo una especie de evangelio inédito y fragmentario (sus "juicios" sobre la sociedad) en papeles que repletan sus bolsillos, hasta desaparecer en los cerros silvestres próximos a Valparaíso. El texto termina con un epílogo que consiste en una supuesta nota de prensa que recoge información de una expedición a Tierra del Fuego, en la que se narra que Agrella no ha muerto sino que se ha convertido en un Dios adorado por las tribus salvajes del fin del mundo. No cabe duda que con ello se ironiza la sentencia huidobriana sobre el poeta como "un pequeño dios", pero también parece darse cuenta de un nuevo giro en la dinámica creativa del auténtico Agrella; en 1924 este publicaba una nueva revista, Nguillatún, cuyo programa ya no miraba a los movimientos europeos ni articulaba un sesgo modernólatra y maquinista, sino que quería ahondar en las raíces vernáculas, el arte, el canto y las costumbres de los grupos raciales araucanos y fueguinos según su expresión, pensando por su propia cuenta las teorías estéticas precursoras de la nueva espiritualidad y proponiéndose realizar arte a la vez "criollo y universal". Agrella, con este manifiesto y también con los relatos de El alfarero indio $(1933)^{8}$, es sin duda el primero y tal vez el único exponente de una eventual vanguardia indigenista en Chile que por cierto se distancia de los desarrollos de vanguardia de la capital, aspecto aún no estudiado, pensándose

\footnotetext{
8 Incluido en Agrella 1999: 175-230.
} 
tal vez que el indigenismo fue únicamente una preocupación de la vanguardia andina, peruana particularmente, y marcada por el pensamiento de Mariátegui.

Los juicios del dios Agrella, en definitiva, sostiene Scholz (1997. En línea), "es una extraña mezcla de distintos géneros, intenciones y también de calidad muy variada, como si lo hubieran escrito Arlt, Macedonio y Borges en equipo". No obstante, habría que considerar a Remenyik como uno de los experimentadores más comprometidos en la aspiración de enlazar arte y vida subyacente a todas las teorizaciones de las vanguardias, que se inclina a favor de la vida: "Oh arte, parece que fuera un jinete pálido y castrado al lado de la vida", afirma en el Cartel $\mathrm{N}^{\circ} \mathrm{III}$ (Remenyik: 79) ${ }^{9}$, propugnando una violenta transformación de la existencia que conlleva una destrucción de todo lo anterior, asunto en que la palabra incendiaria del poeta debe empeñarse adhiriendo a la causa de la revolución social. Sin embargo, este cambiar la vida que compete al poeta se cumple como un rito de autopurificación que le permita junto a los demás vivientes aceptar la moral de la muerte: "Tenemos un deber para con nosotros y para la humanidad: cambiar la vida, y purificarnos hasta que no reconozcamos la moral de la muerte, lo que puede levantarnos en un gesto feliz y dichoso hasta el suicidio" (Remenyik: 79), O sea, se trata del arte como religión frente al desconsuelo y la angustia que acosan en la ciudad:

Por el

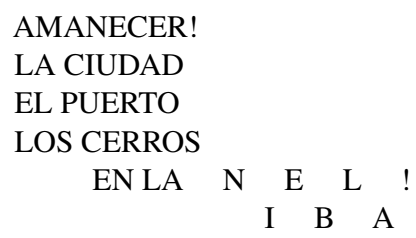

DE LAS CASAS

DE LA NOCHE!

CON TODAS LAS TRAGEDIAS

DE LA VIDA

DE LA HUMANIDAD

puertos hincan la rodilla ante los callejones

LA ANGUSTIA PASO! (Remenyik 57-58)

Una ciudad de la modernidad periférica que es el Valparaíso de la oligarquía burguesa que ya experimenta la decadencia comercial a causa de la apertura del Canal de Panamá y la política de sustitución de las importaciones que se vislumbra después de la Gran Guerra Europea que en los textos de Remenyik se muestra desierta, fantasmal,

\footnotetext{
9 En el Cartel IV exclama: "Llegaré una / vez hasta el punto cuando yo diré / no es necesario / el arte! / voi a negar / la utilidad de la literatura y mandaré / todos los literatos y artistas para la mierda! / vivir la vida es el / arte real!" (Remenyik: 89).
} 
sufriente, escalofriante; un puerto que por las noches suelta sus demonios mientras la peste asola la ciudad. Junto a la crítica social, la escritura de raigambre expresionista de Remenyik despliega una estética de lo grotesco, la desolación, la angustia, la alienación de unos protagonistas trashumantes que se corresponden con unos escenarios urbanos cuya arquitectura se orienta a ser una proyección de la interioridad de los personajes sin importar la lógica constructiva de los espacios. Considerando que el espacio, como afirma Slawinski (2007), es el centro de la semántica de la obra y, por consiguiente, la base de los otros elementos que forman parte de ella ${ }^{10}$, puede sostenerse que las descripciones ecfrásticas de Remenyik, los escenarios que construyen y los sentidos añadidos, permiten hipotetizar que su escritura es resultado del encuentro de la imaginería de la ciudad del activismo expresionista al que adhería Remenyik ${ }^{11}$ con un espacio geográfico y urbano concreto, el de Valparaíso, que de suyo es un escenario expresionista, una arquitectura distorsionada siempre a punto de colapsar, de edificios de fachadas asimétricas, tabernas oscuras, casas colgando de los cerros construidas conforme al temperamento individual de sus habitantes, escaleras inverosímiles, almacenes portuarios abandonados, depósitos, construcciones semiderruidas, calles que se pierden oblicuamente, perspectivas falseadas, luces y sombras angulosas, que no resulta difícil de asociar con el "caligarismo" de los decorados de los filmes de Wiene y sus seguidores, con los que las descripciones espaciales de Remenyik guardan una relevante proximidad. Remenyik advierte atinadamente que la atmósfera (stimmung) de Valparaíso está marcada por la niebla que avanza desde el mar, impregnando las calles, los objetos y los seres, los desdibuja y transformando el Puerto en un paisaje alucinatorio que vacila entre las diluidas sombras grises y los volúmenes netos de edificaciones de contrastantes coloridos. Tal vez sin saberlo, Remenyik en su encuentro con el espacio de Valparaíso, avanzaba desde el expresionismo hacia el verismo de la Neue Sachlichkeit ${ }^{12}$, o al menos se instala en un

10 Slawinski, Janusz (2007), "El espacio en la literatura: distinciones elementales y evidencias introductorias". Criterios, La Habana. Traducción de Desiderio Navarro pp. 1-17 (en línea). "La fábula, el mundo de los personajes, la construcción del tiempo, la situación comunicacional literaria y la ideología de la obra aparecen cada vez más frecuentemente como derivados respecto de la categoría fundamental del espacio" (2). Siendo el espacio "un fenómeno hablado", su constitución transcurre en tres planos de unidades morfológicas de la obra literaria, los que son concebidos también como tres procesos simultáneos de montaje que operan a su vez como diferentes manifestaciones de un mismo proceso semántico: el plano de la descripción, el plano del escenario y el plano de los sentidos añadidos. Este último aspecto que incorpora a los dos anteriores le permite determinar que "[E]l espacio tratado como equivalente de estados emocionales; la oposición entre los espacios realistas y fantásticos [...]: en todos estos casos, y en otros innumerables de género semejante, estamos ante connotaciones que pueden ser movilizadas en la medida en que existan en la obra una sistematización perceptible y programática de los atributos y componentes de los espacios presentados y una axiología ligada a ellos" (16).

11 Un ejemplo sobresaliente del paisaje urbano activista lo constituye el grabado de Bortnyik, Aktivizmus, que acompaña al manifiesto Rosa Náutica.

12 Así describe, por ejemplo, el conocido conventillo La Unión: EN EL CONVENTILLO / "LA UNION" / el conventillo tiene 3 pisos / 53 chimineas y / 248 ventanas por la calle; / aquí vive la PESTE / aquí como y duerme en los catres / grazosos, / colgando sus banderas hediondas por la pared! / las escaleras / con lámparas grises sobre sus espaldas / suben hasta el techo / el conven- / tillo es igual a un cementerio grande en la lluvia triste del otoño (Remenyik: 65) A esta descripción objetiva, sin embargo, se sobrepone otra de carácter fuertemente expresionista en la que el edificio es proyección activa de sus habitantes: "a penas se acostaron bajo las velas azules de la miseria / las paredes / abrieron sus estómagos, las entanas se cayeron por dentro de la pieza / y el techo se levantaba hasta el cielo; / y con gritos espantosos aparecieron los habitantes del conventillo en sus trajes de noche, / entre las ruinas de las paredes y de las ventanas y puertas; (Remenyik: 67). 
tránsito en que conviven los lugares abyectos y atemorizantes con otros que a pesar de su miseria se articulan como metáforas de una desconocida esperanza, según se describen en Los juicios del dios Agrella:

...aquí estában situádós los báres, llamádos Red Stár, Acropolis, El Fáró, i Torpedérás, iluminádos vistosamente! El viejó andaba sin podér orientárse entre lás encrucijadas de lás calles, silbando, [...] i muy muy dolorosamente, autós gaitában en el fondo, i desde lás callejuelás angostás aullidos espantosos eran oidós

i desde lás colinás, que abrazában toda la ciudad, ojos admirablemente ardientes mirában hacia el puertó, con llamas de fanatizmo!

de los ladrones eran estos... (Remenyik: 108)

los ojos

en los cerros vivo en una gran cása, al otro ládó del puertó, en un pequeño cuartó miseráble! Muchas vivimos allá, gentes pobres todás, amontonádás como cachorrós! En el techo tambien viven todavía en una cabana pequena, albaniles de edificios! Parece esta cása a un veléro inmenso con sábanás i camisas tendidás sobre el técho! Viene el viento, i la lléva hacia grandes máres, con nuestros suspiros agotádos, i con nuestrás noches sin sueno en lás cámás impurás (Remenyik: 106).

En definitiva, se trata de un espacio que soporta las contradicciones de la modernidad y que la escritura de Remenyik eleva a categoría de principio formal, sin proponerse trascender tales contradicciones sino, como señala Williams (1989: 49) a propósito del lenguaje expresionista, se trataría de "estados mentales claramente polarizados, condiciones sociales violentamente polarizadas, cuyo conflicto sería entonces la dinámica de la verdad". En esa dinámica, creemos que el sujeto se expresa presionando con toda su energía interior el objeto hasta distorsionarlo, con lo cual adquiere por sí mismo un valor expresivo propio, más allá de la subjetividad que expresa.

\section{EL AULLIDO DE LAS RAMERAS}

El magisterio expresionista de Remenyik es rápidamente recogido por el grupo vanguardista porteño y el mismo año de 1922 se publica el poema de Julio Walton $E l$ aullido de las rameras ${ }^{13}$, texto que discurre entre un debate sobre situación social de las clases marginadas y explotadas, por una parte, pero que termina por decantarse hacia el lenguaje del grito, de la exclamación. En este poema la palabra poética se propone intervenir en los conflictos sociales, como había hecho Walton ya antes con su pequeña pieza de teatro El hijo de nadie (Impresión de 1919), que trata del embarazo de una costurerita del Puerto por parte de un estudiante de Derecho y cómo éste termina por asumir la paternidad y casarse, en contra de los consejos de sus amigos. Agrella (1999: 268) señala que esta comedia mereció el segundo premio en las Fiestas

13 La edición que empleamos se debe a la recuperación que de este texto realizó Scholz en Hispamérica 60, 1992, donde señala: "El aullido de las rameras parece ser el único texto mayor de J. Walton H. El manuscrito, después de unas peripecias verdaderamente surrealistas, recabó [sic] en los fondos de la Biblioteca Nacional de Hungría, en Budapest. El texto, seguramente salvado por Remenyik, es una copia mecanografiada y lleva fecha del 1-2 de Ariosto de 1922" (En nota, Scholz puntualiza: "Véase Remenyikhagyaték, Fond / 109 /12, No 18". 
de la Primavera de Valparaíso en 1911, pero no se representó. Añade que “[M]ás tarde, el 14 de septiembre, la compañía Báguena-Lillo, le estrenó una comedia de más profundidad, Bajo la Garra, cuyo tema, -la embriaguez entre la clase olvidada de los humildes-, está tratado más o menos con acierto". Como puede apreciarse, se trata de temas afincados en los debates de la "cuestión social" y con un notorio sesgo naturalista. Posteriormente Walton participará en la fundación de las revistas porteñas Númen (con el escasamente reconocido poeta Alberto Moreno, traductor de Baudelaire y autor de De las zonas vírgenes) y Siembra que según Agrella (269) fue una "inmejorable revista de arte", pero que al retirarse Walton, "el semanario era una calamidad soportada". Sin embargo, ya el año 22 este propósito había dado paso -sin duda por el magisterio de Remenyik, como lo revelan las similitudes de El aullido de las rameras con La tentación de los asesinos- hacia una "póetica del grito" (Plebe 1971), que resulta de la experiencia urbana de una realidad perturbadora que reclama del poeta un angustioso aullido. En el poema de Walton las rameras que rompen la noche con su aullido funcionan como la sinécdoque de la ciudad (;TODOPODEROSA / MADRE RAMERA!), también su otra cara que la revela históricamente como espacio de incubación de las miserias humanas, vinculando así la ciudad moderna presente (Valparaíso), con la historia universal e inaugurando en el ámbito local un tópico que luego será continuado por otros vanguardistas posteriores como Plonka y Quiñones:

¡Aú! ¡aú! aú! de las ciudades dormidas

¡rompe la densidad de las noches en los pasadizos

$$
\begin{aligned}
& \text { la canalla } \\
& \text { escoria } \\
& \text { coitos }
\end{aligned}
$$

$[\ldots]$

Resuena el

$$
\text { ¡aú! ¡aú! } \quad \text { aú! }
$$

en los descoloridos desvanes transurbanos

de las rameras

[...]

¿Cuándo en los siglos el grito no fue el principio

y el fin? (Walton 77, 78, 80)

Aullido que se relaciona a la comprensión transracional del lenguaje impulsada por las vanguardias. En efecto,

el grito -como sostiene Williams- es un momento conscientemente liberador, verdaderamente revolucionario: el grito puede convertirse en chillido; el grito aún no articulado, en protesta; el grito que lucha por hacerse oír por encima de los noticieros, de los titulares del periódico, de los falsos discursos políticos de un mundo en crisis; incluso el grito puede convertirse en lema, en forma fija para ser gritada como medio de acción colectiva. (1989: 50). 
El aullido se manifiesta entonces como una deformación de la palabra que ya no parece adecuada para expresar la densidad de la realidad y, por lo tanto, el propósito del poeta se orientaba a articular un nuevo lenguaje que diera voz a la otredad, abriendo la cara oculta de lo real.

\title{
VI. CONCLUSIONES PARA UNA VANGUARDiA DIFERENCIAL
}

En el marco de la tradición de ruptura de la vanguardia chilena oficial, en cuya historia se privilegia el impulso y el magisterio del creacionismo huidobriano, su crítica al futurismo, al ultraísmo y su descalificación del surrealismo, se desarrollan con mayor relieve estéticas que suelen tener reminiscencias de corte cubista órfico, como es el caso de Rosamel del Valle, o surrealista, como Díaz Casanueva, o el Neruda de Tentativa del hombre infinito. En todo caso, lo que queda marginado en la periferia provinciana es el sesgo expresionista (y también, parcialmente dadaísta) que a nuestro juicio orienta a la vanguardia porteña (que no por ello deja de incorporar procedimientos constructivos de la imagen creacionista), cuya primera promoción de los años veinte parece culminar en 1929. Dámaso Ogaz, en 1976 recordaba desde Caracas que:

\begin{abstract}
Valparaíso fue en 1929 un punto activo de ruptura con el arte, la literatura y el centralismo "apatronado" de aquellos y estos años. En ese Puerto se realizó, por esa fecha, la primera exposición dentro de los predicados violentos de Dadá y tal vez la única efectuada en el país. Sin embargo todo ese grupo encaminado a reducir al mínimo los efectos de una literatura o arte regulados como mercancía de cuarto orden (provinciana), se quedó en el primer intento. Sirvió como paseíto digestivo. Los brassieres del centralismo que tiene piezas elásticas intercaladas en lugares estratégicos, especialmente en la columna vertebral, terminó por seducir al grupo y su tan especial tipo de colonialismo cultural los hizo dóciles intelectuales. Así terminó la insólita aventura y los brassieres ganaron la partida (Ogaz 1976: 1).
\end{abstract}

Ogaz reconoce así una vanguardia local porteña que parece activa durante algunos años, no obstante habría que puntualizar que esta vanguardia da cuenta, a mi juicio, de una de las dos orientaciones fundamentales que Williams reconoce en el período innovador y experimentador de la modernidad, aquella que "con su comprensión de los cambios que de hecho estaban reformando la sociedad y de los que se derivó extensamente un sentido de futuro y después propiamente de vanguardia" (Williams 1989: 51); orientación a la que paralelamente le acompaña una actitud respecto del lenguaje "comprometida con las formas heredadas y con las posibilidades de la nueva práctica [que] considera el lenguaje como un material dentro de un proceso social" (Williams 1989: 52). Frente a esta actitud, otra vanguardia -en la que podemos situar con claridad el creacionismo y el surrealismo- ve el lenguaje como un entorpecedor de la auténtica conciencia y tiene como base un idealismo intransigente que se limita a encontrar nuevos términos para lo "inefable", la inspiración y el acto creador que estaría en primer plano. Si en la primera comprensión de lo moderno y actitud ante el lenguaje nos encontramos con el expresionismo, ese "ismo" que según Borges sería el único destinado a perdurar, no nos cabe duda que ese compromiso con la historia y con estructuras sociales concretas mediante la formulación de una escritura que 
apuesta a la imagen visual, al efecto de intensidad, conducirá a elaborar una estética firmemente asociada con la experiencia de una ética que percibe y denuncia la vuelta de la barbarie en el decurso de la Historia y, del otro, la utopía social en medio del horror. El gesto expresionista, como indica Foffani (1999. En línea), elabora estéticamente el presente de la Historia como un texto por donde las metáforas extrañas y las alteraciones sintácticas podían representar profundas heridas en el cuerpo de la lengua o bien oníricas visiones en el lenguaje hermético pero colmado de redenciones.

Este es el rasgo que distingue a la vanguardia porteña de las prácticas, que no teorizaciones, de los "brassieres" del centralismo y a su vez explica su extenso desarrollo más allá de los límites reconocidos por las periodizaciones al uso. No obstante, el lapidario juicio de Ogaz desconoce a los herederos del grupo vanguardista inicial de propuestas y prácticas de sesgo expresionista -un expresionismo que debe sin duda matizarse desde su empoderamiento local- que tuvieron su mejor continuación y desarrollo en el, por múltiples razones, más destacado de los poetas de Valparaíso, Guillermo Quiñonez, autor de la Balada de la galleta marinera (publicada solo después de su muerte), y también de Pedro Plonka, cuyo extenso poema El viento y la multitud en la metrópolis solo se conoce parcialmente, de la poesía última de Zoilo Escobar recogida en un interminado y hoy desaparecido manuscrito que habría titulado Las lenguas de fósforo. Tras el grupo fundacional la vanguardia porteña resurgió con nuevos derroteros y así es como en agosto de 1929 surgía en Valparaíso la revista Gong. Tablero de arte $^{14}$, dirigida por Oreste Plath, abriendo "sus dos hojas, como abre sus brazos mal cubiertos, pero sanos ;el proletario al proletario!" a la "inquietud espiritual y artística de los hermanos de América" (Gong, Num. 1: 1) y adoptando una posición vanguardista "contra la oposición de la burla detractora de los mamouth literarios oponiendo la juventud triunfante de Salvador Reyes, Magda Portal, Lucía Condal, Angel Urquieta, Mario Bonat", como lo señala en un número posterior (Gong, Num 4: 1 marzo de 1930 ). Se trata de una diferente versión del vanguardismo -tal vez sería más ajustado calificarlo de arte nuevo- que en Valparaíso desarrollará con empuje lo mejor del imaginismo, lo cual nuevamente dejará al puerto al margen de la literatura metropolitana oficial cuya crítica había tomado partido decidido por el criollismo, tachando injustamente a los imaginistas de exotistas.

En definitiva, la vanguardia de Valparaíso se ha desarrollado como una escritura de la geocultura urbana, que asume el espacio local como hábitat interpretado, lo que la ha determinado como alteridad respecto de la historia literaria nacional. Pero, como bien dice Baudrillard (citado por Belli et al. 2007: 109. En línea) "[L]a alteridad resiste a todo: a la conquista, al racismo, al exterminio, al virus de la diferencia, al psicodrama de la alienación. De una parte, el Otro siempre está muerto; de la otra, es indestructible", lo cual ha terminado por ensamblarla a esa forma de hacer historia que es la memoria colectiva: un cúmulo de representaciones del pasado de las que el

\footnotetext{
14 Gong alcanzó a publicar al menos doce números, siendo el último que se conserva en la Biblioteca Nacional de Chile, el de marzo de 1931. A partir del Num. 4, la revista lleva como subtítulo "Tablero de arte y literatura". En un recuadro central que hace las veces de editorial y que irrumpe en medio del artículo principal titulado "José Carlos Mariátegui" (firmado por Urquieta), Gong cita a "la revista metropolitana Letras" (en la que participarán muchos de los imaginistas) que ha salido en su defensa frente a los ataques que los "mamouth" Pikwick (Raúl Morales Álvarez) y El Duende Gris (Martínez Rubio) le han hecho en aras del "buen gusto”. Termina Gong preguntándose “¿Qué decir ahora de los improvisados críticos porteños?"
} 
medio local se dota a sí mismo para articular los registros de una genealogía cultural que se inscribe en las mentes, las emociones y los ambientes, en la trama de la localidad como un saber identitario de una alteridad que va siendo necesario reconocer en la multiculturalidad que se reclama en nuestra contemporaneidad.

\section{OBRAS CITADAS}

Agrella, Neftalí. 1999. Espiral de humo en lo infinito. Antofagasta: Ediciones Universitarias Universidad Católica del Norte.

Belli, Simona; López, Cristian y Romano, Javier. 2007. "La Excepcionalidad del Otro". Athenea Digital, $\mathrm{N}^{\circ} 11,104-113$. Disponible en http://redalyc.uaemex.mx/pdf/537/53701105. pdf

Compagnon, Antoine. 1990. Les cinq paradoxes de la modernité. Paris: Seuil.

Cruz, Jacqueline. 1997. "Discurso de la modernidad en las culturas periféricas: La vanguardia latinoamericana". Hispamérica 76-77, pp. 19-34.

Edwards, Jacques (Joaquín Edwards Bello). 1979. Metamorfosis. Santiago: Nascimento.

Ferdinandy, Georges. 1975. L'oeuvre hispanoaméricaine de Zsigmond Remenyik. The Hague. Paris: Mouton.

Foucault, Michel. 1967. "Los espacios otros". Disponible en: http://caosmosis.acracia. net/?p=1380

Foffani, Enrique. 1999. Las raíces expresionistas. Fervor vanguardista. Disponible en: http:// edant.clarin.com/suplementos/cultura/1999/08/22/e-01401d.htm

Kusch, Rodolfo. 1976. Geocultura del hombre americano. Buenos Aires: Fernando García Cambeiro.

Lastarria, José Victorino. 1842. "Discurso inaugural de la Sociedad Literaria". Reproducido en José Promis (1995), Testimonios y documentos de la literatura chilena. Segunda edición. Corregida y aumentada. Santiago: Editorial Andrés Bello.

Maestro, Jesús G. 2009. "Crítica contra las interpretaciones contemporáneas sobre el canon literario". Conferencia pronunciada en el XII Simposio Nacional de la Federación de Asociaciones de Profesores de Español. Madrid, 3 de julio. Disponible en: http://academiaeditorial.com/cms/upload/pdf/Critica\%20heterodoxa

Morse, Richard. 2005. "Ciudades 'periféricas' como arenas culturales". Bifurcaciones. Revista Electrónica de Estudios Culturales Urbanos $\mathrm{N}^{\circ} 3$. Disponible en: http://www.bifurcaciones.cl/003/reserva.htm

Nómez, Naín. 1996. Antología crítica de la poesía chilena. Tomo I. Santiago: LOM.

Nora, Pierre. 2009 2002. Les lieux de mémorie. Santiago: LOM.

Ogaz, Dámaso. 1976. La Pata de Palo. Fascículo Nº 6. Caracas, Venezuela.

Oslender, Ulrich. 2002. "Espacio, lugar y movimientos sociales: hacia una 'espacialidad de resistencia". Revista Electrónica de Geografía y Ciencias Sociales, Vol. VI, N 115. Disponible en: http://www.ub.es/geocrit/sn/sn-115.htm

Osorio, Nelson. 1988. Manifiestos, proclamas y polémicas de la vanguardia literaria latinoamericana. (Edición, selección, prólogo, bibliografía y notas). Caracas: Ayacucho.

Plebe, Armando. 1971. Qué es verdaderamente el Expresionismo. Madrid: Doncel.

Plath, Oreste. 1929. Gong. Año I, N 1. Valparaíso.

Remenyik, Zsigmond. 2009. El lamparero alucinado. Edición de László Scholz. Madrid: Iberoamericana.

Rojas Jiménez, Alberto y Martín Bunster. 1920. "El primer manifiesto Agú.” Claridad, Año I, Núm. 6. 
Schwartz, Jorge. 1991. Las vanguardias latinoamericanas. Textos programáticos y críticos. Madrid: Cátedra.

Scholz, Lázló. 1997. "Historia y ficción en Los juicios del dios agrella.” Palimpszeszt, 8 szám, 1997 november. Disponible en: http://magyar-irodalom.elte.hu/palimpszeszt/08_szam/07. htm

Slawinski, Janusz. 2007. "El espacio en la literatura: distinciones elementales y evidencias introductorias". Criterios, La Habana. Traducción de Desiderio Navarro, pp. 1-17. Disponible en: http://criterios.es/pdf/slawinskiespaciolit.pdf

Solar, Claudio. 2001. Historia de la Literatura de Valparaíso. Valparaíso: Gran fraternidad de escritores y artistas de Valparaíso.

Vergara, Sergio. 1994. Vanguardia literaria. Ruptura y restauración en los años 30. Concepción: Ediciones Universidad de Concepción.

Walton, Julio. 1922. "El aullido de las rameras. (Un texto inédito del grupo Rosa Náutica.)" Hispamérica 60, 1992. Estudio y edición de Lászlo Scholz.

Williams, Raymond. 1989. "El lenguaje y la vanguardia". Culler, Derrida et al. La lingüística de la escritura. Madrid: Visor. 
